\title{
A INCERTEZA DO ACESSO À JUSTIÇA EM FACE DA CULTURA DO LITÍGIO: A ascensão de métodos alternativos de resolução de conflitos
}

\author{
THE UNCERTAINTY OF ACCESS TO JUSTICE IN THE \\ CULTURE OF LITIGATION: The rising of alternative \\ dispute resolution
}

\section{Eduardo Silva Luz ${ }^{1}$}

Recebido em: 14/02/2017

Aprovado em: 16/07/2017

\section{RESUMO}

O artigo busca analisar a concretização do direito de acesso à justiça, garantido constitucionalmente e inscrito pelo constituinte dentre o rol dos direitos fundamentais, será apresentado também à importância desse direito como forma de garantia dos demais direitos fundamentais. Esmiuçando os efeitos da justiça moderna nesse direito, sendo que esta passa por um atual momento de crise judiciária, devido à morosidade exacerbada e uma demasiada quantidade de processos que impossibilitam a garantia da justiça. Será analisada também, a cultura do litígio bastante presente na sociedade moderna, como uma das

\footnotetext{
${ }^{1}$ Mestrando em Direito pela Universidade Católica de Brasília. Bolsista pela Coordenação de Aperfeiçoamento de Pessoal de Nível Superior - CAPES . Graduado em Direito pela Associação de Ensino Superior do Piauí-AESPI.
} 
causas do problema no de esgotamento do judiciário, apresentando as atuais reformas legislativas que visam reformar e resolver o problema, principalmente estimulando a utilização de métodos alternativos de resolução de conflitos, como forma adequada de resolver a maioria dos problemas, e propiciando a população a mudança da cultura do litígio para a do consenso, garantindo assim o tão desejado sentimento de justiça.

\section{PALAVRAS-CHAVE}

Acesso à Justiça, Direitos Fundamentais, Cultura do Litígio e Consenso.

\section{ABSTRACT}

The article seeks to analyze an implementation of access to justice, guaranteed constitutionally and inscribed by the Constituent Assembly on the list of fundamental rights, also will be presented the importance of this right as a way of guaranteeing the fundamental rights. Examining the effects of modern justice in that right, that today be passing through a judicial crisis, due to delays exacerbated and an excessive amount of processes that make it impossible to guarantee justice. Also will be examined, the culture of litigation present in modern society, as one of the causes of the problem of exhaustion of the judiciary, showing the current legislative reforms aimed at reform and solve the problem mainly by stimulating the use of alternative methods of conflict resolution, as an appropriate way to solve most problems, and allowing the population to change the culture of litigation to the consensus, thus ensuring the much-desired sense of Justice.

\section{KEYWORDS}

Access to Justice, Fundamental Rights, Culture of Litigation and Consensus 


\section{INTRODUÇÃO}

O presente artigo tem como precipua finalidade apresentar como a utilização de Métodos Alternativos de Resolução de Conflitos também denominados de ADRs - Alternative Dispute Resolution podem ajudar na solução da crise processual pela qual o Judiciário Brasileiro encontra-se, devido ao excesso de processos que aumentam progressivamente todos os dias, em uma taxa que não é possível acompanhar.

Com a data vênia necessária, e correndo risco de ser um pouco superficial, a problemática que hoje se encontra no seio do judiciário brasileiro, assemelha-se por meio de analogia, à crise econômica de 1929, caracterizada como uma crise de superprodução pode-se assim correlacionar ao que acontece atualmente, na qual demasiadamente se judicializa questões, até mesmo questões que podem ser consideradas fúteis, ou que talvez não merecessem o olhar mais aprofundado pelo EstadoJuiz. Entretanto, esse tipo de raciocínio, tem um problema, porque entra em colapso, com a disposição constitucional contida no artigo $5^{\circ}$, inciso $\mathrm{XXXV}$, que de forma rápida afirma que a lei não poderá impedir que o poder judiciário, aprecie qualquer lesão ou ameaça ao direito, esta norma com eficácia imediata com status de direito fundamental, garante a todos as pessoas dentro do território brasileiro, a possibilidade de ter sua questão, analisada pelo poder judiciário, não podendo ser impedido sem uma razão justificável.

Porém, como garantir um processo judicial célere, e que passe a tão desejável sensação de justiça para a população, quando se tem um poder judiciário esgotado e mesmo impossibilitado de agir? A relação da população com o Judiciário, possuí um caráter quase que paternalista, na qual esta desamparada ou mesmo abandonada pelos demais poderes da república recorrem ao judiciário com, os anseios de terem seus direitos fundamentais concretizados e respeitados, contudo toda a engrenagem do judiciário falha quando está sendo forçada demais impossibilitando assim a consecução da própria dignidade humana.

Nesse ponto com a missão de socorrer o judiciário, e desafogá-lo de 
processos, surge-se assim os denominados métodos alternativos de resolução de conflitos buscando a concretização do ideal de justiça e possibilitando com que os resultados sejam alcançados de forma célere, e que satisfaça ambos os lados envolvidos na lide, antes de aprofundar a questão dentro seio do judiciário, entrando na fila de espera processual para que venha a ter um resultado, apenas em alguns anos.

Desta feita, mediação, conciliação e arbitragem, tratam-se de formas que podem ser utilizadas com mais veemência por parte dos interessados, com afã de ter suas questões resolvidas, este procedimento já adotado mundialmente, principalmente quando trata-se de arbitragem internacional, deve ser incentivado pelo Estado brasileiro, afim de resgatar o poder judiciário da crise em que este encontra-se, possibilitando a garantia dos direitos constitucionais da população.

O antigo código processo civil de 1973, mesmo que de forma modesta, já demonstrava por parte do Estado, uma tendência em se priorizar a resolução dos conflitos fora da esfera judicial mas, dentro das denominadas câmaras de conciliação e arbitragem. Com o atual código de processo civil de 2015, consolidou-se a ideia dos métodos alternativos de resolução de conflitos, como uma etapa processual, na qual passou-se tratar de uma função inerente ao Estado-Juiz buscar a conciliação ou mediação entre as partes.

Desta forma, demonstra-se a importância de tais métodos para a consolidação do ideal de justiça, e a pertinência deste artigo que busca estuda-los de forma não a esgotar o tema, mas em fomentar ainda mais o debate sobre esta nova-velha seara do direito, com isso apresentarse-á no decorrer do texto uma visão histórica, características e possibilidades da utilização dos métodos alternativos de resolução de conflitos.

\section{VISÃO HISTÓRICA - DA AUTOTUTELA À JURISDIÇÃO ESTATAL}

Inicialmente, antes de aprofundar o assunto, analisando a evolução das formas de resolução de conflitos é de bom alvitre fazer uma análise filológica das palavras conflito e lide, pois estas tem bastante pertinência 
e relação com o tema, e embora pareça algo simplista vale ressaltar que não são elementos obrigatórios do processo ou seja, não é necessário a existência de conflito para que seja provocada a jurisdição estatal, nesses casos fala-se em jurisdição voluntária.

O conflito trata-se de um problema que está intrinsecamente ligado com a vida em sociedade, inevitavelmente, o contato constante entre seres humanos que possuem anseios e desejos diferentes ou mesmo que as vezes se chocam, acabam por gerar o conflito. O Filosofo Moderno Hegel, em seu livro a Fenomenologia do Espírito, explicita que uma das características fundamentais do Homem, trata-se do desejo de ser desejado, e isso é a razão dos principais conflitos da humanidade.

O jurista italiano Carnelluti explicita fundamentalmente o que para ele seria a gênese do conflito:

A ambição (ou a necessidade) do homem é ilimitada, enquanto os bens ( corpóreos e incorpóreos), passiveis de ser objeto dessa ambição são limitados; a disputa por conseguinte, é inevitável.(CARNELLUTI, 1944 apud TARTUCE, 2008, p.25)

Com isso, analisando as ideias de Hegel e Carnelluti, percebemos que o conflito nasce em razão da vontade humana de ter determinado bem ou seja de uma pretensão a um ou situação de vida e sua impossibilidade de obter, em razão do choque com os interesses de um terceiro.

E hodiernamente o Direito tem a função de ordenar a sociedade, tentando dessa forma resolver esses conflitos, coordenando os interesses que se apresentam no cotidiano em sociedade, e possibilitando a cooperação entre as pessoas, porém o caminho para chegar nesse ponto em que existe todo um aparato legal, voltado para resolver os conflitos não foi uma trajetória simples, e passou-se por momentos de justiça com as próprias mãos até chegarmos na jurisdição estatal. Antônio Cintra, Ada Grinover e Cândido Dinamarco apresentam de concisa, as diversas formas de resolução de conflito:

A eliminação dos conflitos ocorrentes na vida em sociedade pode-se verificar por obra de um ou de ambos os sujeitos dos interesses confli- 
tantes, ou por ato de terceiro. Na primeira hipótese, um dos sujeitos (ou cada um deles) consente no sacrificio total ou parcial do próprio interesse (autocomposição) ou impõe o sacrifício do interesse alheio (autodefesa ou autotutela). Na segunda hipótese, enquadram-se a defesa de terceiro, a conciliação, a mediação e o processo(estatal ou arbitral). (CINTRA, GRINOVER, DINAMARCO, 2012, p.28)

Percebe-se a partir da citação dos eminentes processualistas, a existência clássica de três formas de resolução conflitos, que sejam elas Autotutela (somente admitida em nosso ordenamento, em casos expressos na lei), Auto composição e a Jurisdição Estatal, esta última tem sua a gênese a partir da consolidação do Estado, quando ele chama as atribuições jurisdicionais para sua esfera de competência, passa-se a discorrer sucintamente das três formas.

A primeira forma de resolução de conflitos trata-se da autotutela característica marcante das sociedades primitivas em razão da inexistência de leis e mesmo por um estado incipiente ou mesmo ausente, que não possuía meios que garantissem a ordem e o cumprimento do direito.

Assim a autotutela caracterizava-se por ser o exercício arbitrário do direito subjetivo através da coerção física e moral, a justiça era determinada e feito pelas próprias mãos com a submissão dos mais fracos, aos desejos e anseios daqueles que possuíam mais força para defender os seus direitos, Cintra, Grinover, Dinamarco:

Nas civilizações primitivas, onde não havia um Estado suficientemente forte para superar os ímpetos individualistas dos homens e impor o direito acima da vontade dos particulares, nem sequer existiam as leis a serem impostas pelo Estado sobre os particulares, quem tivesse uma pretensão resistida ou impedida por outrm, trataria de satisfazer essa pretensão através da força física. (CINTRA, GRINOVER, DINAMARCO, 2012, p.28)

$\mathrm{Na}$ esfera penal, esta forma de agir foi denominada de vingança privada, em que a própria pessoa que sofria o dano ou mesmo seus parentes, realizavam a justiça com as próprias mãos em face do autor do crime, mais uma demonstração de uma vontade que se impunha à outra 
pela força sem a intervenção de terceiro.

No atual ordenamento jurídico brasileiro, já não se permite mais a autotutela, exceto nos casos em que a lei prevê e possibilita que seja realizado como nos casos de legítima defesa ou estado de necessidade, bem como nos casos de direito de retenção de imóveis. Entretanto se faz necessário ressaltar que essas hipóteses de autotutela, previstas pelo direito brasileiro, não se assemelha com a mesma autotutela presente em civilizações primitivas, em razão de tratar-se de medidas excepcionais e com limites previstos na própria legislação.

A outra forma de resolução clássica de conflitos trata-se da autocomposição, que embora tenha surgido com as sociedades primitivas, permanece forte no direito atual, se materializando basicamente em três formas, a negociação, mediação e a conciliação. Dessa forma a autocomposição caracteriza-se por uma situação em que uma das partes do conflito ou mesmo as duas, abre mão de seu interesse no todo ou em parte de modo que ambas possam sair satisfeitas, poderiamos vislumbrar como uma forma de ajuste ou entendimento de vontades, afim de dirimir ou acabar com o conflito.

A composição do conflito, através da autocomposição tradicionalmente se dava por meio da desistência, submissão e da transação, mais uma vez cita-se os preclaros doutrinadores processualistas Cintra, Grinover e Dinamarco:

São três as formas de autocomposição (as quais sobrevivem até hoje com referência aos interesses disponíveis): a) desistência (renúncia a pretensão); b)submissão (renúncia a resistência oferecida à pretensão);c) transação (concessões reciprocas). Todas essas soluções têm em comum a circunstância de serem parciais - no sentido que dependem da vontade e da atividade de uma ou de ambas as partes envolvidas. (CINTRA, GRINOVER, DINAMARCO, 2012, p.29)

A autocomposição é a forma mais comum de resolução de conflitos, e principalmente por meio da transação, deveria ser bastante incentivado pelo poder judiciário, pelo seu caráter consensual e altruísta, na qual os próprios membros do litígio procuram a solução mais adequada 
para sua divergência.

Com a progressão da vida em sociedade, e com a complexidade de alguns casos, os indivíduos começaram a procurar uma pessoa imparcial e de confiança mútua, para intervir no conflito, ajudando a encontrar uma solução para a divergência. Inicialmente esse terceiro imparcial, era os sacerdotes ou sábios, que chamavam para si uma função de árbitro, o que iria gerar futuramente o instituto da arbitragem, bastante utilizada atualmente, principalmente para resolução de conflitos no âmbito do direito internacional privado e mesmo no direito interno.

A consolidação do Estado, com o seu poder e soberania dentro do seu território, passou a intervir nos conflitos, chamando para si a competência para a resolução dos conflitos, afim de manter a ordem e a harmonia social. Conflitos antes solucionados de forma privada passaram para a esfera estatal, adquirindo um caráter público pela função jurisdicional do Estado.

A arbitragem que se caracterizava por ser facultativa foi englobada pela função jurisdicional do Estado, que deveria ser provocado, para através dos seus Estado-Juízes, oferecessem soluções aos litígios. Humberto Theodoro Júnior analisa a atividade jurisdicional do Estado da seguinte forma:

Em linhas gerais, a jurisdição caracteriza-se como o poder que toca ao Estado, entre suas atividades soberanas, de formular e fazer atuar praticamente a regra jurídica concreta que, por força do direito vigente, disciplina determinada situação jurídica conflituosa. O processo é o método, o sistema de compor a lide em juízo mediante de uma relação jurídica vinculativa de direito público. Por fim, a ação é o direito público subjetivo abstrato, exercitável pela parte para exigir do Estado a obrigação da prestação jurisdicional. (THEODORO JÚNIOR, 2015, p. 45)

Desta forma, surge a outra forma de resolução de conflitos e consequentemente a mais utilizada pela sociedade em geral hodiernamente, que trata-se da jurisdição estatal, meio esse que foi garantido como direito fundamental, na carta magna de 1988, quando garante ao acesso a justiça. 
Entretanto vale advertir, que a evolução histórica aqui colocada de forma linear, não se deu exatamente dessa forma, seguindo algo cronológico e direto, em razão de que a história da humanidade é marcada por avanços e retrocessos, escolheu-se essa forma de apresentação apenas para manter o caráter didático e facilitar o entendimento de como evoluiu-se de um momento de um Estado incipiente, para um centralizador que tem entre suas funções a tentativa de dirimir conflitos afim de manter a harmonia social.

\section{O ACESSO À JUSTIÇA COMO DIREITO FUNDAMENTAL}

O Constituinte achou por bem positivar o direito de acesso a justiça no rol dos direitos fundamentais, o fez para garantir que este tivesse uma eficácia imediata, e não ficasse apenas no mundo das ideias, mas que fosse concretizado. Tudo isso se deve ao fato de que o acesso a justiça vai servir como alicerce para a garantia dos demais direitos fundamentais, pois é partir deste que se possibilita a efetivação dos direitos individuais, sociais e difusos.

Muito além de apenas uma norma de eficácia imediata, o direito de acesso a justiça contido no artigo $5^{\circ}$, inciso XXXV, encontra-se segundo Cappelletti e Garth envolto de alguns princípios e finalidades:

A expressão "acesso à Justiça” é reconhecidamente de difícil definição, mas serve para determinar duas finalidades básicas do sistema jurídico o sistema pelo qual as pessoas podem reivindicar seus direitos e resolver seus litígios sob os auspícios do Estado. Primeiro, o sistema deve ser igualmente acessivel a todos, ele deve produzir resultados que sejam individual e socialmente justos. (CAPPELLETTI, GARTH, 1988, p.8)

A partir da citação dos eminentes doutrinadores, percebe-se o que alhures já foi comentado, o direito de acesso a justiça, tem uma finalidade exorbitante, pois é a partir dele, que consegue-se efetivar os demais direitos dentro do poder judiciário, para ter a solução de seus conflitos.

Porém, como está claro na citação, para que esse direito seja efetivado de maneira que abranja toda a população, é necessário que esse 
sistema de justiça, ou seja o poder judiciário seja acessivel a todos, principalmente para as camadas mais carentes da população, que são os que mais sofrem principalmente porque para muitos destes, não há dignidade da pessoa humana ou mesmo direito fundamental. Não vive-se mais no século passado, em que somente aqueles que tivessem recursos que pudessem pagar o alto custo do processo, teriam acesso as vias do poder judiciário.

A justiça universal, acessivel a todos e principalmente as classes mais abastadas e carentes da população é a concretização dos ideais do Estado Democrático de Direito, e dos princípios da dignidade humana, provendo a ordem e a paz social.

Quando o Estado possibilita, o acesso universal a justiça, muito além de estar concretizando uma norma ou um princípio constitucional, está na verdade fortalecendo as instituições, e dando uma nova concepção para o próprio Estado em si, como fonte da expressão máxima da cidadania, atendendo os anseios do povo, e possibilitando meios para a prestação de um serviço público eficaz e digno para a sociedade. No mesmo viés vale citar Cintra, Grinover e Dinamarco:

Acesso à justiça não se identifica, pois, com a mera admissão ao processo ou possibilidade de ingresso em juízo. Como se verá no texto, para que haja o efetivo acesso à justiça é indispensável que o maior número possível de pessoas seja admitido a demandar e a defender-se adequadamente (inclusive em processo criminal), sendo também condenáveis as restrições quanto a determinadas causas (pequeno valor, interesses difusos); mas, para a integralidade do acesso à justiça, é preciso isso e muito mais. (CINTRA, GRINOVER, DINAMARCO, 2012, p.42)

Chega-se aqui, ao grande ponto emblemático da questão, a simples garantia do acesso as vias do poder judiciário, através da universalização, que foi permitido por meio de assistência jurídica e da justiça gratuita, possibilitada pela ação das Defensorias públicas, e da redução ou mesmo isenção das custa processuais, para aqueles que se declararem pobres na forma da lei, não resolve o problema nem satisfaz todo o viés do direito constitucional do acesso a justiça, e aqui questiona-se, o que 
é preciso para concretizar esse direito?

A concretização desse direito, encontra-se intimamente ligado também, ao acesso ao Poder Judiciário com uma resposta tempestiva ou seja que não se prolongue demasiadamente no tempo, e através de uma solução efetiva para o conflito com uma participação pragmática e eficaz do Estado, respeitando os direitos fundamentais.

Desta forma, o inciso XXXV do artigo $5^{\circ}$ da Constituição Federal, tem uma melhor interpretação quando este é analisado não apenas como uma garantia do acesso ao judiciário (que por vezes é em demasia burocratizado e deficiente), mas como uma forma de alcance à ordem jurídica justa de forma efetiva, tempestiva e adequada.

Vale ressaltar, que o conceito de acesso a justiça, está totalmente conectado com a satisfação daquele que se socorre no poder judiciário com o resultado final do processo que veem a resolver ao conflito, e não com o mero acesso ao Poder Judiciário, já que este acesso não significa que a pessoa terá o seu problema resolvido.

Nos últimos anos o legislador, atendendo os anseios da população em ter seus problemas resolvidos, e mesmo dos próprios juristas que buscam solução para desburocratizar e desafogar o judiciário, afim de concretizar o direito fundamental de acesso a justiça, tem realizado bastantes mudanças, que analisando algumas de forma cronológicas, podemos citar a partir da Emenda Constitucional $n^{\circ} 45$ de 2004, que contemplava mecanismos voltados para a busca da celeridade e desburocratização das atividades judiciárias. Dentre essas mudanças pode-se citar, a vedação de férias coletivas nos juízos e tribunais de segundo grau, instalação da justiça itinerante.

A resolução $n^{\circ}$ 125/2010 do Conselho Nacional de Justiça, demonstra essa preocupação moderna, quanto ao processo e ao acesso à justiça, e enquadra-se nesse atual movimento de mudanças de paradigmas, socorre-se de novo das palavras dos eminentes doutrinadores, Cintra, Grinover e Dinamarco:

Em relação à mediação e à conciliação, a exposição de motivos da Res. N. 125/2010 do Conselho Nacional de Justiça deixa claro que o inc. XXXV 
do art. $5^{\circ}$ da Constituição, que literalmente trata apenas do acesso ao Poder Judiciário, deve ser interpretado como garantia de acesso à Justiça por qualquer meio adequado de solução de conflitos, como a mediação e a conciliação. (CINTRA, GRINOVER, DINAMARCO, 2012, p.44)

Com isso, para tentar resolver o quadro caótico e complexo dos procedimentos processuais brasileiros, que ao invés de resolver o problema, termina por gerar uma sensação de impotência aos operadores de direito e de injustiça aos que se socorrem do poder judiciário, em razão da demora demasiada na efetivação e conclusão do processo, assim deve-se alargar o conceito de acesso à justiça, que passa a compreender assim os meios alternativos, que atualmente se inserem em um amplo quadro de política judicial.

Mesmo que o código de processo civil de 1973, já prevê-se de forma tímida os meios alternativos de resolução de conflitos, apenas com o código de processo civil 2015, seguindo a tendência dos movimentos que buscam a desburocratização da justiça, foi que o legislador no atual código decidiu observar as diretrizes das resoluções do CNJ, e passou a tornar esses meios consensuais como indispensáveis a justiça, proporcionando a resolução consensual e garantindo a pacificação social.

Vale ressaltar que buscando um processo mais célere e justo, o Código de Processo Civil também trouxe outras inovações, como a simplificação de procedimentos e de atos processuais, e a valorização da jurisprudência do STF e dos Tribunais Superiores, que passam a ser obrigatórias devendo nortear as decisões de todos os tribunais e juízes singulares de todo país, unificando assim o entendimento em certas matérias.

A lei 13.140 de junho de 2015, também tem o condão de melhorar o acesso a justiça, ao regulamentar a mediação, estabelecendo que poderão ser solucionados por meio desta lei, todos os conflitos que envolvam direitos disponíveis e mesmo os indisponíveis que admitam transação, bem como passou a estimular a mediação privada, e prever a possibilidade de contratos possuírem uma cláusula de mediação como opção prévia, antes da abertura do processo.

Analisando todo esse movimento nos últimos anos, percebe-se 
uma tendência à valorização das vias conciliativas, que passam a ser instrumentos de destaques como forma de acesso a justiça, em razão de que o poder judiciário sofre o desgaste da falta de recursos, e em razão da superlotação de processo dentro da via judiciária, estes meios surgem assim como alternativas à morosidade e ao alto custo processual.

\section{DA CULTURA DO LITIGIO AOS MEIOS ALTERNATIVOS DE RESOLUÇÃO DE CONFLITOS - MEDIAÇÃO E CONCILIAÇÃO}

Como alhures explicado, a morosidade processual tende a estrangular os direitos fundamentais do cidadão e não possibilitar a resolução justa do conflito, em razão disso as mudanças que ocorreram no sistema jurídico nacional, nos últimos anos tentam estimular e propiciar a população uma resolução de conflitos a partir do consensualismo resolvendo assim o problema da grande demanda judicial.

Entretanto surge na sociedade de acordo com o avanço das tutelas ou prestação jurisdicionais, uma tendência de resolver tudo desde problemas de grande complexidade até os mais fúteis, dentro da esfera estatal, se socorrendo assim do poder judiciário, algo que muitos doutrinadores têm entendido como uma cultura do litígio.

Voltando a analisar a sociedade brasileira, passou-se a ter uma falsa ideia de que qualquer meio alternativo para a solução de conflito, não terá segurança jurídica ou mesmo encontrar resultados práticos satisfatórios para resolução do problema. Trata-se aqui de uma cultura, que penetrou bem profundamente nas ideias do povo durante sua construção histórica.

Pode-se acrescentar uma outra problemática à cultura do litigio que tem-se na sociedade, que trata-se do caráter paternalista que a população vê no judiciário, muito embora esse poder deva exercer primordialmente um papel contramarjoritário, a população acaba se socorrendo ao poder judiciário a todo instante em razão de se sentir abandonada pelos demais poderes, e afim de terem seus anseios atendidos, judicializam a questão, entrando assim para uma fila de milhares que tam- 
bém tem o mesmo ideal.

Vale ressaltar que, a cultura do litígio da população não é o único motivo ou problema que causa a morosidade no judiciário, considerar isso seria isentar o Estado de qualquer responsabilidade e olhar apenas um viés do problema esquecendo-se assim da alta burocracia e da reforma pela qual o judiciário também necessita passar.

Mas sim, "a cultura do litígio" nos brasileiros é uma das responsáveis pela grande sobrecarga de processos no judiciário, seja em instâncias ordinárias, bem como instâncias superiores, chegando a assustadora marca de 100 milhões de processos, segundo dados mais recentes do Conselho Nacional de Justiça. O número de processos impressiona, bem como é certo que muitos deles, levaram anos para serem concluídos, subindo de grau em grau com recursos, levará bastante tempo para se transformar em coisa julgada.

Fugir da cultura do litígio ou da cultura da sentença em que deixe de se adjudicar todo e qualquer conflito, passando a resolve-lo adequadamente através de métodos consensuais, passa por diversas etapas, que não se implantam imediatamente, e que vai passar por enorme resistência da sociedade.

A sociedade construiu a ideia de que se não judicializar a questão, se não houver os embates homéricos dentro do judiciário, não iria ter sua satisfação e a outra parte controvertida sairá ganhando, qualquer método que fuja disso e que pregue o acordo e o consensualismo, é encarado como derrota e mesmo perca de tempo pela população.

Nesse ponto, ganha extrema importância, a atuação do operador do direito, no intuito de apontar para seu cliente, qual o caminho mais adequado a resolução do conflito que muitas vezes não passa pela tutela jurisdicional, podendo ser resolvido de forma conciliatória ou por meio da mediação, fugindo assim dos grandes problemas existentes dentro do judiciário como a lentidão e altas custas processuais. As benesses da conciliação seja ela realizada extraprocessual ou mesmo no curso da ação (endoprocessual), são diversas tanto para as partes, quanto para o próprio poder judiciário, pois terá questão resolvida em curto espaço de 
tempo e com custo relativamente baixo. Além de que vale ressaltar mesmo em demandas judiciais, a sentença nem sempre vai trazer satisfação plena para o pseudo-vencedor da causa, ao contrário da mediação e conciliação em que busca-se sempre a forma consensual mais adequada para ambas as partes conflitantes.

Desta feita, percebe-se que se faz necessário, uma mudança curricular nos próprios cursos de direitos, para que sejam incentivado aos futuros operadores do direito, que estes devem buscar sempre a solução mais adequada para seus clientes, e fazendo-os perceber, que por vezes essa solução não passa pela prestação jurisdicional estatal quando a causa pode ser resolvida por métodos consensuais, como mediação e conciliação, encerrando-se assim a ideia de senso comum de que advogados devem sempre litigar a questão judicialmente, e demonstrando uma função moderna do operador do direito, que deve exercer uma função de conciliador e mediador.

Outro ponto bastante relevante para tentar mudar a atual situação da cultura do litígio, trata-se de incentivar também a participação dos juízes, estimulando os jurisdicionados em achar uma solução consensual, seja através da mediação e conciliação, que vale ressaltar são atividades complementares e não antagônicos do poder judiciário.

Somente após a mudança da cultura do litígio, é que pode-se falar em métodos alternativos para a resolução de conflitos, pois sem que haja essa mudança, os resultados que poderiam ser obtidos pela mediação, conciliação e arbitragem são inócuos ou ineficientes, principalmente porque a característica principal desses métodos são a voluntariedade e o consensualismo, ou seja é necessário que a população queira utilizar desses meios, não podendo ser forçada, pois estaria contradizendo todo o ideal desse projeto, assim o primeiro ponto como vinha-se retratando no decorrer do texto é a mudança de paradigmas. Vale citar o Roberto Portugal Bacellar:

A verdadeira justiça só se alcança quando os casos "se solucionam" mediante consenso. Não se alcança a paz resolvendo só parcela do problema (controvérsia); o que se busca é a pacificação social do conflito com a solução 
de todas as questões que envolvam o relacionamento entre os interessados. Com a implementação de um novo modelo mediacional, complementar e consensual de solução de dos conflitos, o Estado estará mais próximo da pacificação social da harmonia entre as pessoas. (BACELLAR, 2011, p. 32-33)

Um dos princípios do Estado Democrático de Direito, é buscar principalmente a paz e a harmonia social, propiciando a satisfação e os respeitos dos direitos fundamentais da população, e a solução de conflitos por meios consensuais, é uma forma de concretizar este princípio, pois proporciona à todos uma solução prática e rápida, sem que tenha de passar anos aguardando uma decisão judicial.

Vale ressaltar que o Professor Kazuo Watanbe, em um seminário sobre mediação e arbitragem no dia 21 de novembro de 2014, frisou que "é preciso adotar uma nova cultura que encontre meios adequados de solução de conflitos e não alternativos", ou seja a mediação, conciliação e arbitragem, não devem ser tratadas apenas como meios alternativos a prestação jurisdicional, mas sim, como o meio adequado para a resolução daquele conflito em questão sem a necessidade de provocar a tutela estatal.

A partir desse ponto, passa-se a discorrer genericamente, sobre os três principais meios consensuais de resolução de conflitos, que sejam mediação, conciliação e arbitragem, com a finalidade entender um pouco mais, sobre cada um desses institutos.

A mediação trata-se de um método pacífico de resolução do conflito, por meio da qual um a terceira pessoa que deve ser imparcial, irá conduzir encontros em conjunto ou separado com as partes conflitantes, com a precípua finalidade de incentivar o diálogo entre as partes, para que desse modo possa se alcançar a resolução da contenda em que as partes estão envolvidas. Torna-se bastante pertinente citar a definição de Fernanda Tartuce:

A mediação consiste na atividade de facilitar a comunicação entre as partes para propiciar que estas próprias possam, visualizando melhor os meandros da situação controvertida, protagonizar uma solução consensual [...] o mediador não impõe decisões, mas dirige as regras de comunicação entre as partes. (TARTUCE, 2015, 208) 
Da citação da eminente doutrinadora, é possivel inferir uma das principais características da mediador, que trata-se que este não deve impor decisão (diferenciando de uma sentença), mas sim propiciar um ambiente saudável de diálogo entre as partes conflitantes, assim conclui-se que o objeto principal da medição não é o acordo em si, mas sim a resolução do conflito, a partir do diálogo e a posterior satisfação de todos os envolvidos.

A mediação após a aprovação do Código de Processo Civil de 2015 ganhou bastante destaque, assim como outros meios consensuais de resolução de conflito, e teve logo seu marco regulatório aprovado. Assim a lei 13.140/2015, veio a regular a mediação e definir o seu conceito legal no parágrafo único do artigo primeiro da referida lei, assim como definir atuação do mediador durante todo o processo de mediação, fomentando ainda mais uso deste método para resolução de conflitos.

Após analisar um pouco sobre a mediação, passa-se a discorrer um pouco a respeito de outro método consensual de resolução de conflitos que trata-se da conciliação, assim como a primeira forma apresentada, esta para que possa se concretizar é necessário que as partes queiram conciliar voluntariamente, ou seja é necessário a existência da concordância e futuramente do consenso.

$\mathrm{Na}$ conciliação as partes tem um envolvimento mais importante, com uma participação mais ativa no sentido de tentar resolver o conflito, produzindo assim um compromisso que trata-se do resultado da conciliação sendo estimuladas por um terceiro que adquire o formato de conciliador.

A essência da conciliação é a solução rápida e imediata do problema, tendo um procedimento mais célere, muitas vezes a problemática é resolvida em apenas uma sessão conciliatória, este meio de resolução de conflitos sempre esteve presente em nosso mundo jurídico e por vezes o juiz assumia papel de conciliador, vale citar Tartuce sobre a conciliação em nosso ordenamento:

Em nosso sistema lega, a adoção dos mecanismos "alternativos" sempre se verificou de forma mais acentuada com o incentivo à conciliação. A ideia de estimular a decisão do conflito pelos seus próprios protagonistas, 
sempre esteve presente em nossa legislação processual civil, especialmente pela tentativa de conciliação pelo magistrado (TARTUCE, 2015, p. 90)

Na conciliação, mesmo que sejam as partes à tentar achar um caminho para resolver o conflito, a figura do conciliador possuí grande importância, pois sua atuação deve proporcionar que as partes tenham um ambiente saudável e demonstrar as vantagens de ter o conflito resolvido de forma rápida, mas claro sem prejudicar nenhuma das partes.

A conciliação é o meio mais adequado, para resolver aqueles conflitos em que as partes não tem uma relação interpessoal mais duradoura, ou seja elas se encontraram pela primeira vez ou tem pouco contato, são os casos por exemplo de acidentes de trânsitos, em que as pessoas tem o contato pela primeira vez no momento da ocorrência do problema.

Com o novo Código de Processo Civil a conciliação passou a ter papel de grande destaque sendo constantemente estimulada no decorrer do processo, na qual esta não se apresenta mais apenas com a simples indagação sobre a possibilidade da conciliação, mas tem-se agora uma maior interação entre a as partes e com o juiz exercendo uma função de conciliador apresentando caminhos e sugestões para a solução da demanda.

A conciliação assim como a mediação, são meios consensuais, que servem como uma alternativa, a jurisdição estatal, funcionando assim como meio adequado de concretização da justiça, através de uma resolução célere do problema. Porém, outro meio alternativo ou "adequado" a resolução de conflitos fora da esfera estatal segundo o professor Kazuo Watanabe, trata-se da arbitragem.

A arbitragem ao contrário dos outros métodos alternativos de resolução de conflitos, embora não possua a característica do consensualismo de forma bastante explícita, trata-se uma forma com a peculiaridade bem marcante da voluntariedade pois as partes escolhem a arbitragem para resolver seus problemas em decorrência da morosidade e do excesso de burocracia existentes na jurisdição estatal.

Essa forma de resolução de conflitos é bastante voltada para resolver problemas referentes a direitos patrimoniais, sendo bastante utilizado tanto por empresas no âmbito interno, como internacional. Para 
garantir a eficácia desse método, escolhe-se um especialista na área do problema que melhor decidirá a controvérsia, e neste fato tem-se a diferença primordial entre a arbitragem e a jurisdição estatal, em razão de que no caso da primeira, o problema é resolvido por um especialista da área, o que aumenta as chances de que sua decisão satisfaça ambas as partes conflitantes.

Com isso, muito embora exista uma diferença substancial entre arbitragem e mediação, conciliação, estas caracterizam-se por ser meios voluntários em que as partes querem convergir para um resultado em comum que é ter o conflito resolvido, sem ser necessário provocar a tutela jurisdicional estatal, na qual será caminhado diversos procedimentos burocráticos, para conseguir o tão almejado resultado, que acaba por levar anos. Assim esses meios, apresentam-se como alternativos e adequados para a resolução do conflito.

\section{CONCLUSÃo}

Para muito além de uma análise Filológicos ou mesmo de definição, se são métodos alternativos de resolução de conflitos, ou adequados e mesmo consensuais, como utilizado nesse artigo, a mediação, conciliação e arbitragem se apresentam como a melhor opção disponível, para resolver o problema da morosidade e burocrático da jurisdição estatal.

Não se pode fechar os olhos e não reconhecer que a estrutura do judiciário passa por enormes problemas que impossibilitam a concretização do direito fundamental de acesso a justiça, a tutela estatal já não é mais capaz de atender aos anseios da população, seja pelo excesso de rigor ou mesmo pelo número excessivo de processos, a morosidade tomou conta do judiciário.

Deve-se ressaltar como foi trabalhado no decorrer do presente artigo, o direito fundamental de acesso à justiça garantido pela constituição, não se caracteriza apenas pelo ingresso da população as vias do poder judiciário, é de extrema necessidade que a questão controversa seja resolvida, para somente assim poder se falar de acesso a justiça, as sistemáticas processuais formalistas atuais apenas garantem uma justiça tardia. 
É claro que bastante ligado ao problema do acesso à justiça, reside a questão de que hodiernamente vive-se em uma sociedade baseada na cultura do litígio, na qual todo e qualquer problema por mais pequeno que seja, acaba adjudicado por meio de uma ação, tornando-se assim mais um processo à aparelhar o Poder judiciário.

Com isso, entende-se que para mudar esse panorama caótico, é necessário mudar o entendimento da própria população, incentivando o diálogo e o consenso, buscar resolver a questão sem a necessária provocação do poder judiciário, sendo assim utilizados outros meios que sejam mediação conciliação e arbitragem, como forma de resolução do problema.

O próprio legislador, já entendeu que os meios consensuais, é a forma mais adequada para tratar de certos problemas, podemos perceber essa consciência mais atualizada através do Código de Processo Civil de 2015 e da Lei de Mediação $n^{\circ}$ 13.14-/2015. O acesso à justiça atualmente não se encontra mais intrinsecamente ligado ao âmbito do judiciário moroso, mas sim, às formas mais adequadas de resolver a controvérsia jurídica e garantir os direitos fundamentais.

\section{REFERÊNCIAS}

AZEVEDO, André Gomma (org). Manual de Mediação Judicial. $5^{a}$ edição. Brasília: Conselho Nacional de Justiça. 2015

BACELLAR, Roberto Portugal. O Poder Judiciário e o Paradigma da Guerra na Solução dos Conflitos. In: RICHA, Morgana de Almeida; PELUSO, Antonio Cezar (coords.). Conciliação e Mediação: estruturação da política judiciária nacional. Rio de Janeiro: Forense, 2011

BRASIL. (Constituição 1988). Constituição da República Federativa do Brasil, publicada no Diário Oficial da União n. 191-A, de 05 de outubro de 1988.

CONSELHO NACIONAL DE JUSTIÇA -CNJ. . Dados Estatísticos. 2015. Disponivel em: <http://www.cnj.jus.br/programas-e-acoes/ politica-nacional-de-priorizacao-do-1-grau-de-jurisdicao/dados-estatisticos-priorizacao>. Acesso em: 30 jan. 2016. 
Lei n. 5.869, de 11 de janeiro de 1973. Institui o Código de Processo Civil. Diário Oficial da União. 17.01.1973.

Lei n. 13.105, de 16 de março de 2015. Código de Processo Civil. Diário Oficial da União. 17.3.2015.

Lei n. 13.140, de 26 de junho de 2015. Dispõe sobre a mediação entre particulares como meio de solução de controvérsias e sobre a autocomposição de conflitos no âmbito da administração pública e dá outras providências. Diário Oficial da União. 29.06.2015.

Resolução n. 125 do Conselho Nacional de Justiça, de 29 de novembro de 2010, publicada em $1^{\circ}$ de dezembro de 2010. Dispõe sobre a Política Judiciária Nacional de tratamento adequado dos conflitos de interesses no âmbito do Poder Judiciário e dá outras providências.

CALMON, Eliana. Conciliação Judicial na Justiça Federal. In: RICHA, Morgana de Almeida; PELUSO, Antonio Cezar (coords.). Conciliação e Mediação: estruturação da política judiciária nacional. Rio de Janeiro: Forense, 2011

CAPPELlETTI, Mauro; GARTH, Bryant. Acesso à justiça. Tradução de Elllen Gracie Northfleet. Porto Alegre: Fabris, 1988.

CINTRA, Antônio Carlos de Araújo; GRINOVER, Ada Pellegrini; DINAMARCO, Cândido Rangel. Teoria geral do processo. 28. ed. rev. e atual. São Paulo: Malheiros, 2012.

CONJUR, Consultor Jurídico- et al (Org.). Sem mudança na cultura do litígio, mediação não basta, dizem professores da USP. 2014. Revista Consultor Jurídico. Disponivel em: <http://www.conjur.com.br/2014-nov-23/ mudanca-cultura-litigio-mediacao-nao-basta>. Acesso em: 25 jan. 2016.

TARTUCE, Fernanda. Mediação nos Conflitos Civis. $2^{\text {a }}$ edição. São Paulo: Método, 2015. VirtualBook file. Disponivel em: http://integrada.minhabiblioteca.com.br/books/978-85-309-67215/epubcfi/6/2. Acesso em: 25 jan. 2016

THEODORO JÚNIOR, Humberto. Curso de Direito Processual Civil - Teoria geral do direito processual civil, processo de conhecimento e procedimento comum - vol. I. 56 edição. Rio de Janeiro: Forense, 2015. 